\title{
OPEN Variations in the frequencies of polymorphisms in the CYP2C9 gene in six major ethnicities of Pakistan
}

\author{
Sagheer Ahmed ${ }^{1 凶}$, Nadeem Altaf ${ }^{2}$, Mahnoor Ejaz $^{1}$, Aisha Altaf ${ }^{1}$, Aneela Amin ${ }^{1}$, \\ Kholood Janjua ${ }^{3}$, Arif Ullah Khan ${ }^{4}$, Imran Imran ${ }^{5}$ \& Saeed Khan ${ }^{6}$
}

Genetic variation in cytochrome P450 (CYP) 2 C9 is known to cause significant inter-individual differences in drug response and adverse effects. The frequencies of CYP2C9*2 and CYP 2 C9*3, both of which are responsible for the low activity of the enzyme, are not known in the Pakistani population. Therefore, we screened various ethnic groups residing in Pakistan for these polymorphisms. A total of 467 healthy human volunteers were recruited from six major ethnicities of Pakistan after written informed consent. Our results indicate that about $20 \%$ of the Pakistani population has a genotype containing at least one low activity allele. Ethnic Punjabi and Pathan populations had the highest frequencies of wild type genotypes while Urdu, Seraiki, and Sindhi populations showed higher rates of both low activity genotypes. The Baloch population showed the highest rates of low activity genotypes with less than $50 \%$ of the samples showing wild type genotypes, suggesting that more than half of the Baloch population possesses low activity genotypes. The frequencies found in various ethnic groups in Pakistan were comparable with ethnicities in the South Asian region except for the Baloch population. These results suggest that pharmacogenetics screening for low activity genotypes may be a helpful tool for clinicians while prescribing medications metabolized by CYP2C9.

Genetic polymorphisms in cytochrome P450(CYP) genes can lead to altered enzymatic activity with consequent variation in the pharmacokinetics of a metabolized drug. This variation in the pharmacokinetics of the drug may lead to a change in the response of the drug. It is usually the result of single nucleotide polymorphisms (SNPs) or copy number variations in CYP genes. Therefore, these genetic variants play a crucial role in determining drug pharmacokinetics, non-responder phenomenon, and toxicity ${ }^{1}$. In recent years, these CYP polymorphisms have become important pharmacogenetic biomarkers for drug dosing, efficacy, and safety. However, there is considerable variation in the distribution of CYP alleles in different populations around the world, which may result in variation in drug response and has important implications for personalized treatment.

One of the most important subfamilies of CYP is CYP2C, which consists of four enzymes: CYP2C8, CYP2C9, CYP2C18, and CYP2C19. Of these, the enzyme expressed most abundantly is CYP2C9, which is significantly involved in the metabolism of many important clinical drugs. Based on quantification by mass spectrometry, CYP2C9 is about $20 \%$ of the total hepatic P450 protein content ${ }^{2}$. Another important site of expression is the gastrointestinal tract ${ }^{3}$. CYP2C9 is responsible for the metabolism of approximately $13 \%$ of the drugs metabolized by the cytochrome-catalyzed reactions ${ }^{4}$. Many of these drugs are clinically very important but have a narrow therapeutic index (e.g., warfarin). Therefore, inter-individual variation in CYP2C9 expression and activity may result in inter-individual variation in drug response and safety. Genetic polymorphisms in CYP2C 9 and drugdrug interactions further increase the variation in drug response $e^{1,5,6}$.

CYP2C9 gene contains several variants, but two of the most prevalent, investigated, and influential of them are rs 1799853 and rs1057910, also known as $C Y P 2 C 9^{*} 2$ and $C Y P 2 C 9^{*} 3$ polymorphisms, respectively. $C Y P 2 C 9^{*} 2$ results in an amino acid substitution from Arg to Cys as a consequence of $\mathrm{C}>\mathrm{T}$ transition in the CYP2C9 gene

\footnotetext{
${ }^{1}$ Department of Basic Medical Sciences, Shifa College of Pharmaceutical Sciences, Shifa Tameer-E-Millat University, Sector H-8, Islamabad 44000, Pakistan. ${ }^{2}$ Overseas Pakistanis Foundation Boys College, Sector H-8, Islamabad, Pakistan. ${ }^{3}$ Shifa Clinical Research Center, Shifa International Hospital, Islamabad, Pakistan. ${ }^{4}$ Riphah Institute of Pharmaceutical Sciences, Riphah International University, Islamabad, Pakistan. ${ }^{5}$ Department of Pharmacology, Faculty of Pharmacy, Bahauddin Zakariya University, Multan, Pakistan. ${ }^{6}$ Dow International Medical College, Dow University of Health Sciences, Karachi, Pakistan. ${ }^{\varpi}$ email: sagheer.scps@stmu.edu.pk
} 


\begin{tabular}{|l|l|l|l|l|}
\hline Ethnic group & $\mathbf{n}$ & ${ }^{*} \mathbf{1}(\mathbf{9 5} \% \mathbf{C I})$ & ${ }^{*} \mathbf{2}(\mathbf{9 5} \% \mathbf{C I})$ & ${ }^{*} \mathbf{3}$ (95\% CI) \\
\hline Pakistan & 467 & $0.876(84.61-90.59)$ & $0.059(3.76-8.04)$ & $0.064(4.18-8.62)$ \\
\hline Punjabi & 169 & $0.951(91.85-98.35)$ & $0.034(0.67-6.13)$ & $0.015(-0.33-3.33)$ \\
\hline Pathan & 79 & $0.943(89.19-99.41)$ & $0.032(-0.68-7.08)$ & $0.025(-0.94-5.94)$ \\
\hline Urdu & 64 & $0.820(72.59-91.41)$ & $0.064(1.14-12.25)$ & $0.101(5.67-19.39)$ \\
\hline Seraiki & 55 & $0.882(79.69-96.73)$ & $0.046(-0.94-10.14)$ & $0.073(0.43-14.17)$ \\
\hline Balochi & 50 & $0.620(48.55-75.45)$ & $0.160(5.84-26.16)$ & $0.220(10.52-33.48)$ \\
\hline Sindhi & 50 & $0.830(72.59-93.41)$ & $0.090(1.07-16.93)$ & $0.080(0.48-15.51)$ \\
\hline
\end{tabular}

Table 1. Allelic frequencies of various ethnic groups in Pakistan.

at position 430 (c.430C > T, p.Arg144Cys). CYP2C9³ causes an amino acid substitution from Ilu to Leu as a result of a transversion, $\mathrm{A}>\mathrm{T}$ in the CYP2C9 gene (c.1075A $>\mathrm{C}$, p.Ile359Leu) ${ }^{7}$. The activity of CYP2C9 is significantly reduced as a result of these polymorphisms, and in the Caucasian population, they are responsible for a majority of decreased CYP2C9 activity phenotypes ${ }^{7}$. Both of these variations decrease the rate of phenytoin hydroxylation ${ }^{8}$. Hydroxylation of S-warfarin is impaired by $C Y P 2 C 9^{*} 2^{6}$, while the metabolism of tolbutamide is decreased by $\mathrm{CYP} 2 \mathrm{C}^{*} 3^{9}$. Benzo[a]pyrene, an important lung carcinogen, is also metabolized by CYP2C9, and therefore, SNPs in this gene also carry the risk of lung cancer ${ }^{10}$. Therefore, these SNPs not only affect drug response and adverse effects, but they are also associated with certain disease phenotypes.

Interpopulation differences in drug responses are well known, and in some cases, they correspond to differences in the frequency of associated genetic markers, especially CYP genes. That is why differences in CYP2C9 allele distribution have been described for various populations. Pakistan is a culturally diverse country, but little is known about the distribution of CYP2C9 genetic polymorphism in this country of over 200 million people. Therefore, we intended to determine the frequencies of these polymorphisms in the Pakistani population, with samples drawn from six of its most populous ethnic groups. We specifically investigated the samples of various ethnic populations from Pakistan to examine the frequencies of $C Y P 2 C 9^{\star} 1, C Y P 2 C 9^{\star} 2$, and $C Y P 2 C 9^{\star} 3$ and then compared them with previous findings in other populations.

\section{Results}

Allelic frequencies. The allelic frequencies of $C Y P 2 C 9^{\star} 1, C Y P 2 C 9^{\star} 2$, and $C Y P 2 C 9^{\star} 3$ in the Pakistani population were found to be $0.876,0.059$, and 0.064 , respectively (Table 1 ), while for the ethnic Punjabi population, the frequencies were $0.951,0.034$, and 0.015 respectively. In the ethnic Pathan population, the observed frequencies were in a similar range $\left(0.943,0.032,0.032\right.$ for $C Y P 2 C 9^{\star} 1, C Y P 2 C 9^{\star} 2$, and $C Y P 2 C 9^{\star} 3$, respectively). In Urdu speaking population, the rate of $C Y P 2 C 9^{*} 1, C Y P 2 C 9^{*} 2$, and $C Y P 2 C 9^{*} 3$ were slightly different at 0.820 , 0.078 , and 0.023 , respectively. The Seraiki population was found to have $C Y P 2 C 9^{*} 1, C Y P 2 C 9^{*} 2$, and $C Y P 2 C 9^{*} 3$ at frequencies of $0.882,0.46$, and 0.73 , respectively. The results obtained from the Baloch population diverged significantly. In the Baloch population, the frequencies of $C Y P 2 C 9^{*} 1, C Y P 2 C 9^{\star} 2$, and $C Y P 2 C 9^{*} 3$ were found to be $0.620,0.160$, and 0.220 , respectively, whereas, in the Sindhi population, the frequencies were $0.830,0.090$, and 0.080 respectively (Table 1 ).

Genotype frequencies. The observed genotype frequencies were $80.3 \%$ for $C Y P 2 C 9^{\star} 1^{\star} 1,6.2 \%$ for $C Y P 2 C 9^{\star} 1 * 2,8.4 \%$ for $C Y P 2 C 9^{\star} 1 * 3,0.6 \%$ for $C Y P 2 C 9^{\star} 2^{\star} 2$ and $4.5 \%$ for $C Y P 2 C 9^{\star} 2^{\star} 3$ in Pakistani population (Table 2). No one was found to be homozygous for CYP2C9*3*3. Genotype frequencies in Punjabi, Pathan, Urdu, Seraiki, Baloch, and Sindhi populations are shown in Table 2. In the Punjabi population, all the genotype frequencies except $C Y P 2 C 9^{*} 3^{\star} 3$ were present, whereas, in the Pathan population, no CYP2C $9^{\star} 2^{\star} 3$ and $C Y P 2 C 9^{*} 3^{*} 3$ genotypes were observed. While the Pathan population lacked $C Y P 2 C 9^{*} 2^{\star} 3$ and $C Y P 2 C 9^{\star} 3 * 3$ genotypes, Urdu and Seraiki speaking populations were deficient in $C Y P 2 C 9^{\star} 2^{\star} 2$ and $C Y P 2 C 9^{*} 3^{\star} 3$ genotypes. The genotype frequencies of the Baloch population were significantly different from other ethnic groups. In the Baloch population, the frequencies of $C Y P 2 C 9^{\star} 1^{\star} 1$ were comparatively low at $46 \%$, and decreased activity genotypes were considerably higher. Like Urdu and Seraiki populations, the Baloch population also lacked $C Y P 2 C 9^{*} 2^{*} 2$ and $C Y P 2 C 9^{*} 3^{*} 3$ genotypes. This was also true for the Sindhi population in which the frequencies of $C Y P 2 C 9^{*} 1^{\star} 1$ were comparable to the Urdu speaking population (Table 2 ).

Comparison with worldwide populations. Comparison with the worldwide and regional populations revealed significant differences in the frequencies of $C Y P 2 C 9^{\star} 2$. Colombian, Puerto Rican, Spanish, and Italian populations showed significantly higher frequencies while Han Chinese, Bengali, and Indian Telugu population displayed a significantly low frequency of $C Y P 2 C 9^{*}$. Frequencies of this allele in Mexican, Peruvian, Finnish, British, Gujrati Indian, and Sri Lankan Tamil populations were not statistically different from Pakistani frequencies (Table 3). Allelic frequencies of CYP2C9*3 in Peruvian and Chinese Dai populations were found lower than the Pakistani population, while Bengali and Gujrati Indian populations showed significantly higher frequencies (Table 4). CYP2C $9^{\star} 3$ frequencies in Colombian, Mexican, Puerto Rican, Han \& Southern Han Chinese, Japanese, Vietnamese, Finnish, British, Spanish, Italian, Sri Lankan Tamil, and Indian Telgu populations were not statistically different from Pakistani frequencies observed in our investigation (Table 4). Frequencies of CYP2C $9^{\star} 2$ and $C Y P 2 C 9^{*} 3$ frequencies in Pakistanis from Lahore were also in agreement with our study (Table $3 \& 4$ ). 


\begin{tabular}{|c|c|c|c|}
\hline Genotype & n & Observed genotype frequency (CI) & Expected genotype frequency by $\mathrm{HW}$ law \\
\hline \multicolumn{4}{|l|}{ Pakistani } \\
\hline${ }^{\star} 1^{\star} 1$ & 375 & $80.3(76.7-83.9)$ & 79.85 \\
\hline${ }^{\star} 1{ }^{\star} 2$ & 29 & $6.2(4.02-8.38)$ & 7.08 \\
\hline${ }^{*} 1 * 3$ & 39 & $8.4(5.89-10.91)$ & 8.00 \\
\hline${ }^{\star 2} 2$ & 3 & $0.6(0.1-1.3)$ & 0.16 \\
\hline${ }^{\star} 2 * 3$ & 21 & $4.5(2.62-6.38)$ & 4.91 \\
\hline \multicolumn{4}{|l|}{ Punjabi } \\
\hline${ }^{\star} 1^{\star} 1$ & 155 & $91.7(87.54-95.86)$ & 91.75 \\
\hline${ }^{\star} 1{ }^{\star} 2$ & 8 & $4.7(1.51-7.89)$ & 4.58 \\
\hline${ }^{*} 1 * 3$ & 4 & $2.4(0.09-4.71)$ & 2.36 \\
\hline${ }^{\star 2} 2$ & 1 & $0.6(0.0-1.76)$ & 0.05 \\
\hline$\star^{\star} * 3$ & 1 & $0.6(0.0-1.76)$ & 1.24 \\
\hline \multicolumn{4}{|l|}{ Pathan } \\
\hline${ }^{\star} 1^{*} 1$ & 72 & $91.1(84.48-97.72)$ & 88.70 \\
\hline${ }^{\star} 1 * 2$ & 1 & $1.3(0.0-3.93)$ & 6.00 \\
\hline${ }^{\star} 1 * 3$ & 4 & $5.1(0.0-10.22)$ & 4.96 \\
\hline${ }^{\star} 2{ }^{\star} 2$ & 2 & $2.5(0.0-6.13)$ & 0.10 \\
\hline${ }^{\star 2 * 3}$ & 0 & 0.0 & 0.24 \\
\hline \multicolumn{4}{|l|}{ Urdu } \\
\hline${ }^{\star} 1^{\star} 1$ & 46 & $71.9(60.89-82.91)$ & 72.0 \\
\hline${ }^{\star} 1{ }^{\star 2}$ & 5 & $7.8(1.23-14.37)$ & 7.41 \\
\hline${ }^{\star} 1 * 3$ & 8 & $12.5(4.4-20.6)$ & 11.57 \\
\hline${ }^{\star 2} 2$ & 0 & 0.0 & 0.19 \\
\hline${ }^{*} 2^{*} 3$ & 5 & $7.8(1.23-14.37)$ & 6.83 \\
\hline \multicolumn{4}{|l|}{ Seraiki } \\
\hline${ }^{\star} 1^{\star} 1$ & 44 & $80.0(69.43-90.57)$ & 80.00 \\
\hline${ }^{\star} 1{ }^{\star} 2$ & 3 & $5.5(-0.53-11.53)$ & 5.32 \\
\hline${ }^{\star} 1 * 3$ & 6 & $10.9(2.66-19.14)$ & 10.24 \\
\hline${ }^{\star 2} 2$ & 0 & 0.0 & 0.08 \\
\hline${ }^{\star 2 * 3}$ & 2 & $3.6(-1.32-8.52)$ & 4.36 \\
\hline \multicolumn{4}{|l|}{ Balochi } \\
\hline${ }^{\star} 1^{\star} 1$ & 23 & $46.0(32.19-59.81)$ & 46.44 \\
\hline${ }^{\star} 1{ }^{\star} 2$ & 5 & $10.0(1.68-18.32)$ & 9.10 \\
\hline${ }^{\star} 1 * 3$ & 11 & $22.0(10.52-33.48)$ & 18.44 \\
\hline${ }^{\star 2} 2$ & 0 & 0.0 & 0.40 \\
\hline${ }^{\star} 2 * 3$ & 11 & $22.0(10.52-33.48)$ & 25.62 \\
\hline \multicolumn{4}{|l|}{ Sindhi } \\
\hline${ }^{*} 1^{*} 1$ & 35 & $70.0(57.3-82.7)$ & 70.58 \\
\hline${ }^{\star} 1 * 2$ & 7 & $14.0(4.38-23.62)$ & 12.83 \\
\hline${ }^{*} 1 * 3$ & 6 & $12.0(2.99-21.01)$ & 11.12 \\
\hline${ }^{\star} 2^{\star} 2$ & 0 & 0.0 & 0.58 \\
\hline$* 2 * 3$ & 2 & $4.0(-1.43-9.43)$ & 4.89 \\
\hline
\end{tabular}

Table 2. Genotype frequencies of various ethnic groups in Pakistan.

\section{Discussion}

Pakistan is one of the most populous countries in the world, with an estimated population of over 220 million people. Pakistan boasts a relatively young population that comes from diverse cultural and ethnic backgrounds. Despite being home to one of the biggest populations in the world, studies investigating genetic variations responsible for drug response are scarce. There are several dozen ethnic groups in Pakistan. However, the six ethnicities we selected for our study represent more than $94 \%$ of the Pakistani population. The biggest ethnic group in Pakistan are Punjabis, followed by Pathan, Sindhi, Saraiki, Urdu, and Baloch ethnic groups. A geographical map indicating the regions where selected ethnicities primarily reside and the distribution CYP2C9 genetic frequencies in those ethnicities are shown in Fig. 1.

The allelic frequencies of $C Y P 2 C 9^{*} 2$ and $C Y P 2 C 9^{*} 3$ observed in the present study were found to agree with previously reported frequencies around the world (Table $3 \& 4$ ). The frequency of $C Y P 2 C 9^{\star} 1$ in Pakistan was closest to the one found in America. However, the frequency of $C Y P 2 C 9{ }^{\star} 2$ was higher in the American population, and CYP2C $9^{\star} 3$ was slightly higher in the Pakistani population ${ }^{11}$. In South Asia, Bangladesh was found to 


\begin{tabular}{|l|l|l|l|l|}
\hline Population & CYP2C9*1 & CYP2C9 ${ }^{*} \mathbf{2}$ & Chi-square statistic & p-value \\
\hline CLM & 165 & 23 & 9.30 & 0.002285 \\
\hline MXL & 115 & 13 & 3.20 & 0.073297 \\
\hline PEL & 166 & 4 & 3.71 & 0.053976 \\
\hline PUR & 179 & 29 & 15.59 & 0.000079 \\
\hline CHS & 209 & 1 & 11.03 & 0.000895 \\
\hline CEU & 168 & 30 & 19.50 & 0.000010 \\
\hline FIN & 182 & 16 & 1.19 & 0.274819 \\
\hline GBR & 166 & 16 & 2.71 & 0.099223 \\
\hline IBS & 184 & 30 & 16.17 & 0.000058 \\
\hline TSI & 181 & 33 & 21.62 & 0.000010 \\
\hline BEB & 169 & 3 & 5.19 & 0.022599 \\
\hline GIH & 196 & 10 & 0.40 & 0.525495 \\
\hline ITU & 199 & 5 & 4.14 & 0.041707 \\
\hline PJL & 182 & 10 & 0.17 & 0.72285 \\
\hline STU & 198 & 6 & 3.03 & 0.081610 \\
\hline
\end{tabular}

Table 3. Comparison of $C Y P 2 C 9^{\star} 2$ allelic frequencies observed in Pakistan with other populations. CLMColombian in Medellin, Colombia, MXL-Mexican ancestory in Los Angeles, California, PEL-Peruvian in Lima, Peru, PUR-Puerto Rican in Puerto Rico, CHS-Southern Han Chinese, China, CEU-Utah residents with northern and western European ancestory, FIN-Finnish in Finland, GBR-British in England and Scotland, IBSIberian population in Spain, TSI-Toscani in Italy, BEB-Bengali in Bangladesh, GIH-Gujrati Indian in Houston, TX, ITU-Indian Telgu in UK, PJL-Punjabi in Lahore, Pakistan, STU-Sri Lankan Tamil in the UK.

\begin{tabular}{|l|l|l|l|l|}
\hline Population & CYP2C9*1 & CYP2C9*3 & Chi-square statistic & p-value \\
\hline CLM & 176 & 12 & 0.00 & 0.983300 \\
\hline MXL & 125 & 3 & 3.35 & 0.066859 \\
\hline PEL & 168 & 2 & 7.47 & 0.006268 \\
\hline PUR & 199 & 9 & 1.31 & 0.250987 \\
\hline CDX & 181 & 5 & 3.95 & 0.046597 \\
\hline CHB & 198 & 8 & 1.94 & 0.163451 \\
\hline CHS & 200 & 10 & 0.82 & 0.363867 \\
\hline JPT & 204 & 4 & 6.51 & 0.10700 \\
\hline KHV & 191 & 7 & 2.44 & 0.117672 \\
\hline CEU & 185 & 13 & 0.00 & 0.941230 \\
\hline FIN & 187 & 11 & 0.20 & 0.647096 \\
\hline GBR & 169 & 13 & 0.12 & 0.719721 \\
\hline IBS & 196 & 18 & 1.08 & 0.297420 \\
\hline TSI & 196 & 18 & 1.08 & 0.297420 \\
\hline BEB & 152 & 20 & 5.86 & 0.015470 \\
\hline GIH & 179 & 21 & 10.69 & 0.001076 \\
\hline ITU & 183 & 20 & 3.79 & 0.051460 \\
\hline PJL & 173 & 2.94 & 0.086270 \\
\hline STU & 184 & 2.92 & 0.087132 \\
\hline
\end{tabular}

Table 4. Comparison of $C Y P 2 C 9^{*} 3$ allelic frequencies observed in Pakistan with other populations. CLMColombian in Medellin, Colombia, MXL-Mexican ancestory in Los Angeles, California, PEL-Peruvian in Lima, Peru, PUR-Puerto Rican in Puerto Rico, CDX-Chinese Dai in Xishuangbanna, China CHB-Han Chinese in Beijing, China, CHS-Southern Han Chinese, China, JPT-Japanese in Tokyo, Japan, KHV-Kinh in Ho Chi Minh City, Vietnam, CEU-Utah residents with northern and western European ancestory, FIN-Finnish in Finland, GBR-British in England and Scotland, IBS-Iberian population in Spain, TSI-Toscani in Italy, BEBBengali in Bangladesh, GIH-Gujrati Indian in Houston, TX, ITU-Indian Telgu in UK, PJL-Punjabi in Lahore, Pakistan, STU-Sri Lankan Tamil in the UK. 


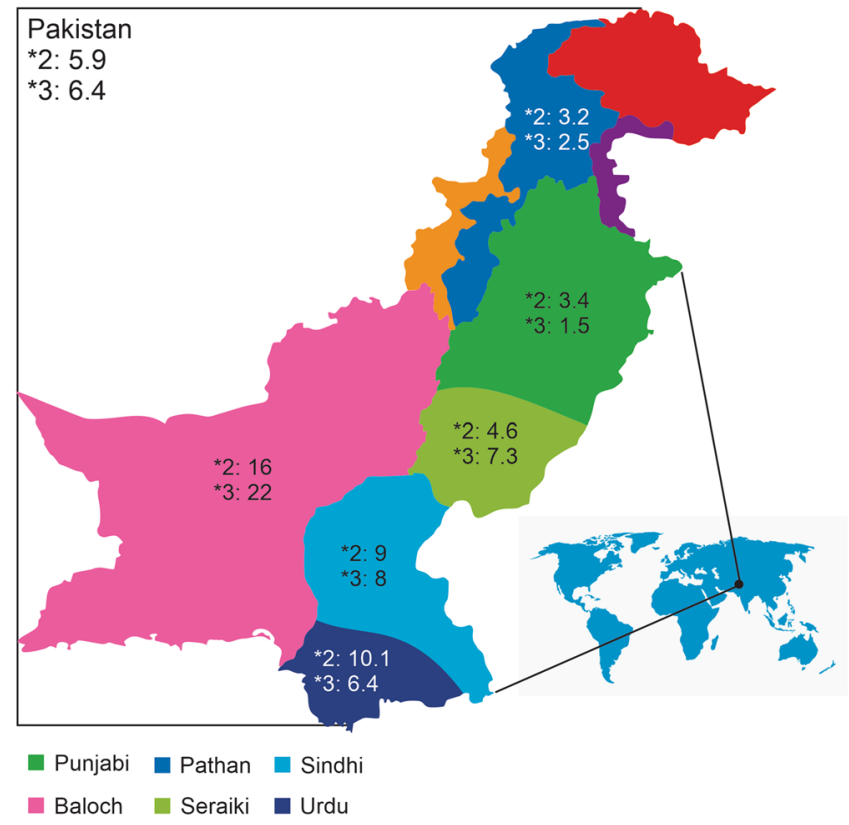

Figure 1. Geographical representation of the ethnic groups investigated in the study. The figure was created using CorelDRAW Graphic Suite 2020 (https://www.coreldraw.com/en/).

have a similar frequency of $C Y P 2 C 9^{\star} 1$, but the frequency of $C Y P 2 C 9^{\star} 2$ in Bangladesh was significantly low, and that of CYP2C9 9 was significantly high compared to what was observed in Pakistani population ${ }^{12}$ (Table $3 \& 4$ ).

Frequencies of $C Y P 2 C 9^{\star} 2$ were relatively high in the Pakistani population compared to many Asian populations such as Japanese, Korean, Chinese Taiwanese, in which this allele was absent ${ }^{7,13,14}$. Many regional populations such as Indians and Sri Lankans did show significant differences in frequencies of $C Y P 2 C 9^{\star} 2$ allele ${ }^{15-18}$. However, the Pakistani population displayed slightly lower frequencies of this allele compared to regional populations such as in Bengali and Gujrati Indians. Among the European populations, Swedish, Turkish ${ }^{19-21}$, Spanish and Italian populations had higher frequencies (Table 3) while Finnish and British populations, while displaying higher frequencies, were not statistically different from Pakistani population. The frequencies of the $C Y P 2 C 9^{*} 3$ allele in the Pakistani population were found to be similar to many European populations, including British, Finnish, Spanish, and Italian (Table 4). However, Peruvian and Chinese Dai populations showed statistically lower frequencies. Frequencies of $C Y P 2 C 9^{\star} 3$ found in some regional population such as Bengalis and Gujrati Indians, were higher while in others, such as in Indian Telugu, and Sri Lankan Tamil were in agreement with our results (Tables 3,4 ).

Among different ethnicities, Punjabi and Pathan populations had the highest frequencies of the CYP2C $9{ }^{\star} 1$ allele, while the $C Y P 2 C 9^{*} 2$ allele frequencies were also in a similar range. However, $C Y P 2 C 9^{\star} 3$ frequencies were different between these two ethnicities, with the Pathan population showing much greater frequencies compared to the Punjabi population. Urdu and Seraiki populations had slightly lower frequencies of the wild type allele compared to Punjabi and Pathan populations. However, the allelic frequency of $C Y P 2 C 9^{*} 2$ was higher in the Urdu speaking population, while CYP2C ${ }^{*} 3$ was found higher in the Seraiki population. Baloch populations samples showed results very different from any other ethnic population. The baloch population had the lowest frequency of wild type allele, while the frequency of $C Y P 2 C 9^{\star} 2$ was the highest among Pakistani populations. Similarly, the Baloch frequencies of $C Y P 2 C 9^{*} 3$ were also the highest among Pakistani ethnicities. The pattern in the Sindhi population was similar to Urdu and Seraiki populations.

While analyzing genotype frequencies, Punjabi and Pathan population samples showed similar frequencies of wild type genotype, CYP $2 C 9^{\star} 1^{\star} 1$. However, unlike Punjabi population samples, Pathan population samples lacked the CYP2C $9^{*} 2^{*} 3$ genotype (Table 2 ). Urdu and Seraiki population samples, although having similar frequencies of wild type allele, had different wild type genotypes. This implies that roughly $30 \%$ of the Urdu speaking population has a CYP2C9 genotype with at least one low activity allele. This was found to be true for the Sindhi population as well in which the frequencies of $C Y P 2 C 9^{*} 1^{\star} 1$ were reported to be $70 \%$. In the Baloch population, wild type CYP2C9 genotype was reported in only $46 \%$ samples, and therefore, indicates that more than half the population may possess at least one low activity allele (Table 2). This represents a significant fraction of the Baloch population with a potentially variable response and/or enhanced adverse effects when drugs metabolized by CYP2C 9 are administered.

The Pakistani population is a heterogeneous mixture of Asian, Middle Eastern, and European populations partly because of the Arab invasion of the eighth century and British invasions of the eighteenth and nineteenth centuries, and partly owing to its high geographic and ethnic diversity ${ }^{22}$. The genetic structure of various Pakistani populations have been analyzed and several distinct variants identified among different ethnicities by global projects such as the 1000 Genome Project and Human Genome Diversity project ${ }^{12,23}$. Some studies indicate 
that the genetic structure of these ethnicities is closely related to both South Indian and European populations ${ }^{24}$ while others suggest Pakistani ethnicities to be similar to European populations ${ }^{25,26}$. The extreme differences observed in the Balochi population may be due to their diverse ancestry belonging to Aryan, Arab, Persian, Turkish, Kurdish, Dravidian, Sewais, and black African lineages ${ }^{27}$.

Genetic information about patients' CYP2C9 gene is likely to help physicians prescribe to patients the most suitable and safest drug based on their genetic make-up. With roughly $13 \%$ clinically available drugs metabolized by CYP2C9 enzyme 28 and over 2.6 billion unit doses of drugs dispensed in Pakistan annually, the number of unit doses metabolized by the CYP2C 9 enzyme in Pakistan annually is over 332 million. Our study shows that about $20 \%$ of Pakistan's population has a CYP2C9 genotype that contains at least one low activity allele. These results indicate that over 66 million doses of drugs dispensed annually in Pakistan may not have desired effects as patients receiving these medications possess a low activity CYP2C9 allele. In patients receiving a drug that requires activation through $\mathrm{CYP} 2 \mathrm{C} 9$, a lack of response could be expected. On the contrary, if a drug is inactivated by CYP2C9, then increased frequency and severity of adverse effects would be a more likely outcome. With CYP2C9 genotype information at hand, physicians will have a choice to change the drug or dose of the drug to provide maximum therapeutic benefit to the patient and/or prevent the undesired and excessive adverse effects.

To our knowledge, this is the first study to report frequencies of CYP2C9 gene polymorphisms in various ethnicities of the Pakistani population. Although there have been a few studies from Pakistan in which frequency of $C Y P 2 C 9^{*} 2$ and $C Y P 2 C 9^{*} 3$ were reported ${ }^{29-31}$, all of these studies involved patients with different diseases and, therefore, unable to capture the actual frequency of these polymorphisms in a general Pakistani population. The frequencies of $C Y P 2 C 9^{*} 2$ and $C Y P 2 C 9^{*} 3$ reported in these publications are $5.1 \%$ for $C Y P 2 C 9^{\star} 2$, $15.4 \%$ for $C Y P 2 C 9^{\star} 3$ in breast cancer patients ${ }^{29}, 4.45 \%$ for $C Y P 2 C 9^{\star} 2,22.8 \%$ for $C Y P 2 C 9^{\star} 3$ in cardiovascular patients taking warfarin ${ }^{31}$ and $12.1 \%$ for $C Y P 2 C 9^{*} 2,14.1 \%$ for $C Y P 2 C 9^{\star} 3$ in heart valve replacement patients taking warfarin ${ }^{30}$. These frequencies vary significantly from one study to another and are also different from the ones we have reported for the healthy Pakistani population in this study. Frequencies of both low activity alleles were significantly higher in these studies than what we observed in our study. For example, frequencies of the $C Y P 2 C^{*} 3$ allele were four times higher in one of these studies and more than twice higher in the rest of the two studies. This may be because some polymorphisms are associated with certain diseases, and therefore, their frequencies in the patient groups would be different from a normal healthy population. Large differences in the sample size in these studies could also partly explain the variations observed in allelic frequencies. Another publication reporting the CYP2C9 gene polymorphisms in the Pakistani population also had participants who were heart valve replacement patients taking warfarin ${ }^{32}$. However, the allelic frequencies reported in that study were in agreement with ours, although the frequencies of $C Y P 2 C 9^{*} 2$ were slightly on the lower side. This study was carried out in patients with Punjabi ethnicity only. Furthermore, patient samples reported in these studies were obtained from a single geographical location and, therefore, may not represent entire Pakistan, which is a large country with a population of over 220 million people having varied ethnic backgrounds.

In conclusion, both the $C Y P 2 C 9^{*} 2$ and $C Y P 2 C 9^{*} 3$ allelic variants are found in the Pakistani population, and $C Y P 2 C 9^{*} 3$ was slightly more common than $C Y P 2 C 9^{\star} 2$. One limitation of our study is we were unable to find the true $C Y P 2 C 9^{*} 1$ allele due to the genotyping method we employed in our research study. Individuals were genotyped $C Y P 2 C 9^{\star} 1$ when neither $C Y P 2 C 9^{\star} 2$ nor $C Y P 2 C 9^{\star} 3$ was detected. Most of the polymorphisms demonstrated in our study were heterozygous. No $C Y P 2 C 9^{*} 3^{*} 3$ homozygosity was seen in our study, and only 3 (less than $1 \%$ ) were homozygous for $C Y P 2 C 9^{*} 2^{*} 2$. This suggests that the homozygous polymorphism is rare in the Pakistani population. The frequency of these polymorphisms was found to be slightly different in different ethnic populations in Pakistan except for Baloch population samples, which showed an unusually high frequency of these polymorphisms. We recommend that genotyping of the CYP2C9 gene in patients on drugs such as warfarin, phenytoin, etc., may help to overcome the drug toxicity, chose the right alternative, and guide in therapeutic drug monitoring.

\section{Methods}

The study was approved by the Institutional Review Board and Ethics Committee of Shifa Tameer-e-Millat University, Islamabad, Pakistan, through approval number IRB\#990-265-2018. Informed written consent was obtained from all participating individuals. All experiments were performed in accordance with relevant guidelines and regulations. A total of 467 unrelated individuals from a healthy population were recruited for the present study. The study cohort consists of six major ethnicities of Pakistan, including Punjabis, Pathan, Sindhi, Balochi, Seraiki, and Urdu speaking. Ethnicity was self-reported. Five milliliters of venous blood was drawn into a sterile tube containing EDTA as an anti-coagulant and were stored at $4^{\circ} \mathrm{C}$. Genomic DNA was isolated using Gene Jet Genomic DNA extraction Kit (ThermoScientific) and was quantified using 1\% agarose gel electrophoresis. Isolated genomic DNA was stored at $-20^{\circ} \mathrm{C}$ until further processing ${ }^{33}$.

Genotyping. CYP2C $9{ }^{\star} 2$ and ${ }^{*} 3$ were genotyped using ARMS-PCR (Allele Refractory Mutation SystemPolymerase Chain Reaction) using a pair of outer primers and a pair of inner primers as described previously ${ }^{34}$. PCR for both the SNPs was performed in a single tube with a total reaction volume of $25 \mu$ l containing $12.5 \mu \mathrm{l}$ of $2 \mathrm{X}$ Dream Taq Master mix (ThermoScientific), $0.5 \mathrm{pM}$ of $2 \mathrm{C} 9^{\star} 2$ wild type reverse primer, $1.5 \mathrm{pM}$ of $2 \mathrm{C} 9^{\star} 2$ mutant reverse primer, $3.0 \mathrm{pM}$ of common forward primer, $1.0 \mathrm{pM}$ of $2 \mathrm{C} 9^{\star} 3$ wild type forward primer, $2.0 \mathrm{pM}$ of $2 \mathrm{C} 9 * 3$ mutant forward primer, $3.0 \mathrm{pM}$ of common reverse primer and $3 \mu \mathrm{l}$ of template DNA $(20-50 \mathrm{ng} / \mu \mathrm{l})$. Thermal profile was as follows: initial denaturation at $95^{\circ} \mathrm{C}$ for $10 \mathrm{~min}$ followed by 37 cycles with denaturation at $95^{\circ} \mathrm{C}$ for $45 \mathrm{~s}, 45 \mathrm{~s}$ of primer annealing at $58^{\circ} \mathrm{C}$, initial extension at $72^{\circ} \mathrm{C}$ for $45 \mathrm{~s}$, and a final extension at $72^{\circ} \mathrm{C}$ for $7 \mathrm{~min}$. For visualization, $12 \mu \mathrm{l}$ of PCR product was directly loaded onto $4 \%$ agarose gel. The PCR products for $2 \mathrm{C} 9^{\star} 2$ had $105 \mathrm{bp}$ fragment for the wild type allele and $114 \mathrm{bp}$ fragment for the mutant allele, whereas $2 \mathrm{C} 9^{\star} 3 \mathrm{had}$ 
$159 \mathrm{bp}$ fragment for the wild type allele and $168 \mathrm{bp}$ fragment for the mutant allele. Individuals were genotypes $2 \mathrm{C} 9^{\star} 1$ when neither $2 \mathrm{C} 9^{\star} 2$ nor $2 \mathrm{C} 9^{\star} 3$ was detected. More than one-quarter of the total samples were sent for sequencing to validate further the results obtained through ARMS-PCR.

Statistical analysis. Allelic Data were compiled according to the genotype and allele frequencies estimated from the observed numbers of each specific allele. The frequency of each allele and genotype in our samples is given together with the $95 \%$ confidence interval. The confidence interval for proportions was calculated using the formula $(\mathrm{CI}=\mathrm{p} \pm(1.96 \times \mathrm{SE}), \mathrm{SE}=\mathrm{qrt}[\mathrm{p}(1-\mathrm{p}) / \mathrm{n}], \mathrm{p}=$ proportion, $\mathrm{n}=$ sample size $)$. Chi-squared test and $\mathrm{p}$ values were calculated using observed and expected frequencies as per the Hardy-Weinberg equation.

Ethical statement. The study was approved by the Institutional Review Board and Ethics Committee of the Shifa International Hospital and Shifa Tameer-e-Millat University, Islamabad, Pakistan.

Received: 10 July 2020; Accepted: 16 September 2020

Published online: 09 November 2020

\section{References}

1. Zhou, S.-F., Zhou, Z.-W., Yang, L.-P. \& Cai, J.-P. Substrates, inducers, inhibitors, and structure-activity relationships of human Cytochrome P450 2C9 and implications in drug development. Curr. Med. Chem. 16, 3480-3675 (2009).

2. Zhang, H.-F. et al. Physiological content and intrinsic activities of 10 cytochrome $\mathrm{P} 450$ isoforms in human normal liver microsomes. J. Pharmacol. Exp. Ther. 358, 83-93 (2016).

3. Paine, M. F. et al. The human intestinal cytochrome P450 'pie'. Drug Metab. Dispos. Biol. Fate Chem. 34, 880-886 (2006).

4. Isvoran, A. et al. Pharmacogenomics of the cytochrome P450 2C family: impacts of amino acid variations on drug metabolism. Drug Discov. Today 22, 366-376 (2017).

5. Zhou, S.-F., Zhou, Z.-W. \& Huang, M. Polymorphisms of human cytochrome P450 2C9 and the functional relevance. Toxicology 278, 165-188 (2010)

6. Rettie, A. E. \& Jones, J. P. Clinical and toxicological relevance of CYP2C9: drug-drug interactions and pharmacogenetics. Annu. Rev. Pharmacol. Toxicol. 45, 477-494 (2005).

7. Yoon, Y.-R. et al. Frequency of cytochrome P450 2C9 mutant alleles in a Korean population. Br. J. Clin. Pharmacol. 51, 277-280 (2001).

8. Veronese, M. E. et al. Site-directed mutation studies of human liver cytochrome P-450 isoenzymes in the CYP2C subfamily. Biochem. J. 289, 533-538 (1993).

9. Relling, M. V., Aoyama, T., Gonzalez, F. J. \& Meyer, U. A. Tolbutamide and mephenytoin hydroxylation by human cytochrome P450s in the CYP2C subfamily. J. Pharmacol. Exp. Ther. 252, 442-447 (1990).

10. London, S. J., Daly, A. K., Leathart, J. B., Navidi, W. C. \& Idle, J. R. Lung cancer risk in relation to the CYP2C $9^{*} 1 / \mathrm{CYP} 2 \mathrm{C} 9^{\star} 2$ genetic polymorphism among African-Americans and Caucasians in Los Angeles County, California. Pharmacogenetics 6, 527-533 (1996).

11. Sullivan-Klose, T. H. et al. The role of the CYP2C9-Leu359 allelic variant in the tolbutamide polymorphism. Pharmacogenetics 6, 341-349 (1996).

12. Auton, A. et al. A global reference for human genetic variation. Nature 526, 68-74 (2015).

13. Th, S.-K. et al. The role of the CYP2C9-Leu359 allelic variant in the tolbutamide polymorphism. Pharmacogenetics 6, 341-349 (1996).

14. Nasu, K., Kubota, T. \& Ishizaki, T. Genetic analysis of CYP2C9 polymorphism in a Japanese population. Pharmacogenetics 7, 405-409 (1997).

15. Adithan, C. et al. Allele and genotype frequency of CYP2C9 in Tamilnadu population. Eur. J. Clin. Pharmacol. 59, 707-709 (2003).

16. Chaudhary, N. et al. Frequencies of CYP2C9 polymorphisms in North Indian population and their association with drug levels in children on phenytoin monotherapy. BMC Pediatr. 16, 66 (2016).

17. Jose, R. et al. CYP2C9 and CYP2C19 genetic polymorphisms: frequencies in the south Indian population. Fundam. Clin. Pharmacol. 19, 101-105 (2005).

18. 1000 Genomes | A Deep Catalog of Human Genetic Variation. https://www.internationalgenome.org/.

19. Stubbins, M. J., Harries, L. W., Smith, G., Tarbit, M. H. \& Wolf, C. R. Genetic analysis of the human cytochrome P450 CYP2C9 locus. Pharmacogenetics 6, 429-439 (1996).

20. Yasar, U. et al. Validation of methods for CYP2C9 genotyping: frequencies of mutant alleles in a Swedish population. Biochem. Biophys. Res. Commun. 254, 628-631 (1999).

21. Sükrü Aynacioglu, A. et al. Frequency of cytochrome P450 CYP2C9 variants in a Turkish population and functional relevance for phenytoin. Br. J. Clin. Pharmacol. 48, 409-415 (1999).

22. Bhatti, S., Aslamkhan, M., Attimonelli, M., Abbas, S. \& Aydın, H. H. Mitochondrial DNA variation in the Sindh population of Pakistan. Austral. J. Forensic Sci. https://doi.org/10.1080/00450618.2016.1144788 (2017).

23. Bergström, A. et al. Insights into human genetic variation and population history from 929 diverse genomes. Science 367, eaay5012 (2020).

24. Metspalu, M. et al. Shared and unique components of human population structure and genome-wide signals of positive selection in South Asia. Am. J. Hum. Genet. 89, 731-744 (2011).

25. Ayub, Q. et al. Reconstruction of human evolutionary tree using polymorphic autosomal microsatellites. Am. J. Phys. Anthropol. 122, 259-268 (2003).

26. Mansoor, A. et al. Investigation of the Greek ancestry of populations from northern Pakistan. Hum. Genet. 114, 484-490 (2004).

27. Ahmed, M. \& Khan, G. The history of Baloch and Balochistan: a critical appraisal. 14.

28. Zanger, U. M. \& Schwab, M. Cytochrome P450 enzymes in drug metabolism: regulation of gene expression, enzyme activities, and impact of genetic variation. Pharmacol. Ther. 138, 103-141 (2013).

29. Afsar, N. A. et al. Genotype frequencies of selected drug metabolizing enzymes and ABC drug transporters among breast cancer patients on FAC chemotherapy. Basic Clin. Pharmacol. Toxicol. 107, 570-576 (2010).

30. Yasmeen, F. et al. Analysis of CYP2C9 polymorphisms ( ${ }^{*} 2$ and ${ }^{*} 3$ ) in warfarin therapy patients in Pakistan. Association of CYP2C9 polymorphisms ( ${ }^{*} 2$ and ${ }^{\star} 3$ ) with warfarin dose, age. PT and INR. J. Thromb. Thrombolysis 40, 218-224 (2015).

31. Qayyum, A. et al. Frequency of common CYP2C9 polymorphisms and their impact on warfarin dose requirement in Pakistani population. Clin. Appl. Thromb. Off. J. Int. Acad. Clin. Appl. Thromb. 23, 800-806 (2017).

32. Siddiqi, A., Khan, D. A., Khan, F. A. \& Naveed, A. K. Impact of CYP2C9 genetic polymorphism on warfarin dose requirements in Pakistani population. Pak. J. Pharm. Sci. 23, 417-422 (2010).

33. Ahmed, S. et al. Genetic variations in drug-metabolizing enzyme CYP2C9 among major ethnic groups of Pakistani population. Gene 746, 144659 (2020). 
34. Funk, M. et al. CYP2C9² and CYP2C9³ alleles confer a lower risk for myocardial infarction. Clin. Chem. 50, 2395-2398 (2004).

\section{Acknowledgments}

The authors wish to thank Shifa Tameer-e-Millat University, Islamabad, for funding and for providing an excellent academic environment to facilitate this kind of scholarly activity. The sponsors had no role in the design, execution, interpretation, or writing.

\section{Author contributions}

S.A. and S.K. conceptualized the study. A.U.K., S.K. and I.I. searched the literature and provided samples, M.E., A.A. and A.A. collected the data, and helped in manuscript preparation. S.A., N.A., and K.J. helped prepare the manuscript. S.A., S.K., and K.J. refined the manuscript for publication. All authors read and approved the final manuscript for publication.

\section{Funding}

This research was carried out from funds given to Dr. Sagheer ahmed by Shifa Tameer-e-Millat University, Islamabad.

\section{Competing interests}

The authors declare no competing interests.

\section{Additional information}

Correspondence and requests for materials should be addressed to S.A.

Reprints and permissions information is available at www.nature.com/reprints.

Publisher's note Springer Nature remains neutral with regard to jurisdictional claims in published maps and institutional affiliations.

(c) (i) Open Access This article is licensed under a Creative Commons Attribution 4.0 International License, which permits use, sharing, adaptation, distribution and reproduction in any medium or format, as long as you give appropriate credit to the original author(s) and the source, provide a link to the Creative Commons licence, and indicate if changes were made. The images or other third party material in this article are included in the article's Creative Commons licence, unless indicated otherwise in a credit line to the material. If material is not included in the article's Creative Commons licence and your intended use is not permitted by statutory regulation or exceeds the permitted use, you will need to obtain permission directly from the copyright holder. To view a copy of this licence, visit http://creativecommons.org/licenses/by/4.0/.

(C) The Author(s) 2020 